\title{
WHEAT BLAST DETECTION AND ASSESSMENT COMBINING GROUND-BASED HYPERSPECTRAL AND SATELLITE BASED MULTISPECTRAL DATA
}

\author{
Rahul Nigam ${ }^{1, *}$, Bimal K. Bhattacharya ${ }^{1}$, Rajsi Kot $^{2}$ and Chirantan Chattopadhyay ${ }^{3}$ \\ ${ }^{1}$ Agriculture and Land Eco-System Division, Space Applications Centre, (ISRO), Ahmedabad 380 015-rahulnigam@ sac.isro.gov.in \\ ${ }^{2} \mathrm{M}$ G Science College, Ahmedabad \\ ${ }^{3}$ Uttar Banga Krishi Viswavidyalaya Pundibari, Coochbehar, West Bengal
}

Commission III, WG III/10

KEY WORDS: Wheat Blast, Vegetation Index, RS-2, AWiFS

\begin{abstract}
:
Remote sensing-based large-area crop disease discrimination plays a vital role in agricultural management to assess severity level of diseases to avoid economical losses to farming community. Over the period, various biotic stresses have emerged through disease and pest infestation. Among these, blast is one of the most disastrous disease of wheat. It is also called as leaf blast, collar rot node blast, spike blast or rotten neck blast depending on the portion of wheat infected. Wheat blast is caused by the fungal pathogen Magnaporthe oryzae and first discovered in Brazil, Bolivia and Paraguay in 1985. In 2017, wheat blast was emerged in Murshidabad district of West Bengal in India. This posed a serious threat to Indian food security. In this study blast disease over wheat crop is studied using ground based hyperspectral measurements at one nm interval and Resourcesat-2 AWiFS data for year 2017. Supervised classification with maximum likelihood classifier was used to generate wheat crop mask using AWiFS data. The ground based hyperspectral bands are further used derive four RS-2 AWiFS broad spectral bands and showed significant difference in healthy and infested plants in vegetative and advance vegetative stages in green, red, NIR and SWIR spectral bands. The 2-D scatter between vegetative indices such as NDVI and LSWI showed well-marked discrimination between healthy and infested wheat crop in all sites. These results are used to derive thresholds for NDVI and LSWI and translated in RS-2 AWiFS derived indices to generate disease severity at spatial scale over Murshidabad district of West Bengal. The distributed wheat severity map showed that 0.59 percent and 99.41 percent of total wheat area is healthy and blast infested respectively. This study suggests that wheat blast can be discriminated using RS-2, AWiFS broad bands at vegetative and advance vegetative stage with support of ground measured hyperspectral data and damage area can be mapped at spatial scale before final harvest.
\end{abstract}

\section{INTRODUCTION}

A large gap exists between the potential yield and actual realized yield at the agricultural field. There are many factors such as biotic and abiotic stresses, which contribute towards this yield gap. Plant disease discrimination and forecasting plays a vital role in agricultural management to predict the occurrence and severity level of diseases to avoid economical losses to farming community. Prediction and assessment of plant disease and infestation by traditional field based exercises are extremely tedious, time consuming, high in labour cost and produces low efficiency. Field survey of disease and pest infestation is unfeasible for larger scale. Remote sensing can overcome all such limitations with ability to access larger areas and can achieve high spatial, temporal and spectral resolution remote sensing data. Precise knowledge about occurrence, epidemiology and symptomatology provides a systematic tool to policy makers to establish action plan regarding demand of essential insecticide and pesticide during crop growing season. Combined application of multispectral and hyperspectral remote sensing techniques provides rapid, non-destructive and cost effective remedies for identification and quantification of disease and pest infestation. The response of plants varies with the interaction of different wavelength regions of the electromagnetic radiation. The same plant demonstrates the difference in reflectance due to varied health conditions. Occurrence and severity of disease infestation can be estimated according to difference in spectral characteristics of healthy and diseased plant.
Wheat is the most important crop for global food security and nutritional requirement to a majority population of world. Over the period, advanced cultivation practices, various genotypes and various biotic and abiotic stress have emerged (Saharan et al., 2016). Among these, blast is one of the most disastrous disease of wheat. It is also called as leaf blast, collar rot node blast, spike blast or rotten neck blast depending on the portion of wheat infected. Wheat blast is caused by the fungal pathogen Magnaporthe oryzae (Couch \& Kohn, 2002) Triticum pathotype (Murakami et al., 2000) (MoT, synonym Pyricularia oryzae, Triticum, pathotype) and first discovered in Brazil, Bolivia and Paraguay. Almost $15 \%$ of wheat area in Bangladesh was affected by wheat blast disease (Callaway, 2016; Saharan et al., 2016). Most severe wheat blast outbreaks are reported in wet years, warm temperature and high humidity conditions. Wheat blast fungus infects all the above ground parts of the plant but most common symptom is spike infection. The spike infection can occur on the glumes, awns and rachis along with elliptical lesions with red to brown to dark grey margins and white to light brown centres are observed. Symptoms on heads can vary from elliptic lesions and bleached centres, spike bleaching, sterility and empty grains depending upon the time and stage of infection. In the late infection of wheat blast, it may lead to seed borne inoculum to the next crop. Leaf lesions vary in the shape, size and margin depending on the stage of the plants. This lead to a serious threat for food and income security for South Asia where inhabitants consume over 100 million tons of wheat per year. Moreover, present economic condition and awareness of farming community of these regions allows the spread of the disease, which can severely harm wheat production in South Asia. In 2017, wheat blast emerged in Murshidabad district of 
West Bengal in India. This will pose a serious threat to Indian food security hence immediate and effective measures should be taken to inhibit the disease. This motivate us to study response of healthy and diseased wheat crop over electromagnetic spectrum and how can these spectral data to discriminate them. Keeping in view over threat posed by wheat blast present study is planned with the following objectives: (i) generation of spectral signature of wheat blast infestation using hyperspectral data (ii) identification multispectral bands sensitive spectral bands for discrimination between healthy and disease infested crops and (iii) assessment of wheat blast infested area.

\section{STUDY AREA}

Present study is conducted over Murshidabad district of West Bengal. This area is in the middle of West Bengal lying between $23^{\circ} 43^{\prime} \mathrm{N}$ and $24^{\circ} 52^{\prime} \mathrm{N}$ latitude and $87^{\circ} 49^{\prime} \mathrm{E}$ and $88^{\circ} 44^{\prime} \mathrm{E}$ longitude. Murshidabad has a tropical wet and dry climate. The annual mean temperature is approximately $27^{\circ} \mathrm{C}$; monthly mean temperature ranges from $17^{\circ} \mathrm{C}$ to $35^{\circ} \mathrm{C}$. Summers are hot and humid with temperatures between $30^{\circ} \mathrm{C}$ to $35^{\circ} \mathrm{C}$ and during dry spells; the maximum temperature often exceeds $40^{\circ} \mathrm{C}$ during May and June. Winter tends to last for only about two and half months with seasonal lows dipping to $9^{\circ} \mathrm{C}-11^{\circ} \mathrm{C}$ between December and January. Rains brought by the Bay of Bengal branch of south-west monsoon lash the district between June and September. It supplies the district with most of its annual rainfall approximately $1600 \mathrm{~m}$

\section{DATA USE}

\subsection{Ground based spectral data:}

Canopy reflectance data is obtained with ASD spectroradiometer with different sampling intervals across spectral region of 350 to $2500 \mathrm{~nm}$ (1 nm interval) over six randomly selected sites of Murshidabad district of West Bengal.

\subsection{Satellite data:}

The multi-date Resourcesat-2 Advanced Wide Field Sensor (AWiFS) data of the study region mentioned above is used. It observe earth's surface in four optical bands (green (0.52-0.59 $\mu \mathrm{m})$, red $(0.62-0.68 \mu \mathrm{m})$, NIR $(0.77-0.86 \mu \mathrm{m})$ and SWIR $(1.55-1.70 \mu \mathrm{m}))$ having spatial resolution of $56 \mathrm{~m}$. AWiFS have a radiometric resolution of 10 bits has swath of $740 \mathrm{~km}$ with five day receptivity. The cloud free AWiFS data over study regions were acquired for wheat seasons during 2017.

\section{METHODOLOGY}

Wheat crop spectral signature has been measured from $350 \mathrm{~nm}$ to $2500 \mathrm{~nm}$ wavelength to characterize healthy and blast infested plant. Atmospheric perturbation bands which lie between 1350 to $1420 \mathrm{~nm}$ and 1800 to $2020 \mathrm{~nm}$ and 2370 to $2500 \mathrm{~nm}$ has been neglected for the analysis of ground spectral profile over wheat crop. In situ data is analysed at $1 \mathrm{~nm}, 5 \mathrm{~nm}$ and further scaled up to four AWiFS spectral bands to distinguish between healthy and blast infested wheat crop. Laboratory calibrated AWiFS sensor's spectral response function is used to convolute $1 \mathrm{~nm}$ ground data to four broad multispectral bands of the respective sensor. The unpaired t-test has been applied over all four bands to test the null hypothesis that the population means related to two independent, random samples from an approximately normal distribution are equal.

\subsection{Generation of top of the atmosphere reflectance}

Resourcesat-2 AWiFS clear sky data of $22^{\text {nd }}$ and $16^{\text {th }}$ February for year 2016 and 2017 respectively has been used to generate top of the atmosphere (TOA) reflectance for all four bands. To generate TOA, first, digital number (DN) is converted to atsensor cross-calibrated band radiances (LTOA) using equation 3.

$L_{\text {TOA }}=\frac{D N}{\text { MaxGaycownt }}\left[L_{\max }-L_{\min }\right]+(\mathrm{Lmin})$

Where $\mathrm{L}_{\max }$ is saturated radiance, $\mathrm{L}_{\min }$ is minimum radiance; DN is digital number respectively for all four bands. For each AWiFS band radiance is calculated by using $\mathrm{L}_{\max }$ and $\mathrm{L}_{\min }$ as per metadata file. After the computation of radiance for each AWiFS band TOA reflectance is derived using equation 2 .

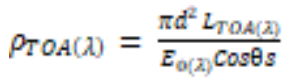

Where $\mathrm{LtOA}_{\mathrm{T}(\lambda)}$ is $\mathrm{Wm}^{-2} \mu \mathrm{m}^{-1} \mathrm{sr}^{-1}$, $\mathrm{d}$ the Earth-Sun distance correction factor and calculated using equation 5 .

$d=(1-0.01672 \times \cos (0.9856 \times($ C. day -4$)))$

$\mathrm{E}_{0(\lambda)}$ is the exo-atmospheric band pass irradiances weighted through relative spectral response (RSR) at fixed wavelength interval for specific band, C.day is the Calendar day and $\theta_{s}$ the solar zenith angle (degree).

\subsection{Generation of wheat crop mask}

Supervised classification with maximum likelihood algorithm is used to generate wheat crop mask. Based on stated algorithm wheat crop area has been classified using all four bands AWiFS as well as ground truth points at 56-meter spatial scale.

\subsection{Computation of Vegetation indices}

The $\rho_{\text {TOA }(\lambda)}$ AWiFS band is for further used for computation of vegetation indices such as Normalized Difference Vegetation Index (NDVI) and Land Surface Water Index (LSWI). NDVI is an indicator of the amount of green biomass (Tucker et al., 1986).

$$
\text { NDVI }=\frac{\rho_{\text {WHFR }}-\rho_{\text {REE }}}{\rho_{\text {WHF }}+\rho_{\text {RiED }}}
$$

$$
\begin{aligned}
& \text { LSWI }= \\
& \frac{p_{\text {WHRR }}-p_{\text {SWHR }}}{p_{\text {WHR }}+p_{\text {SWHR }}}
\end{aligned}
$$

\section{RESULTS AND DISCUSSION}

\subsection{Spectral signature for disease infested wheat crop}

The spectral properties of crop are mainly determined by their biophysical and biochemical attributes such as leaf area index (LAI), the amount alive and senesced pigment, biomass and moisture content and spatial arrangement of cells and structures. The general shape of reflectance and transmittance curves for green leaves is similar for all species with variation in the magnitude of reflectance. Plant spectral response to electromagnetic radiation is controlled by absorption features of specific molecules and the cellular structure of the leaf tissue. The measured spectral response of wheat crop for healthy and 
diseased infested over ground site at Murshidabad district of West Bengal is shown in Figure 1. Spectral response of healthy and different classes of disease infestation showed difference in red, red edge, NIR and SWIR-1 and SWIR-2 band regions in terms of curvature and magnitude. The primary cause of variation in the red and red edge region is due to deviation in the leaf chlorophyll content between healthy and diseased wheat crop. This has been observed in the ground observed chlorophyll content. Overall $61 \%$ deviation is observed between chlorophyll content of healthy and blast infested plant. The decrease in chlorophyll content in blast affected wheat plant causes decrease in red band absorption in the crop and is reflected in observed ground measured spectral profile.

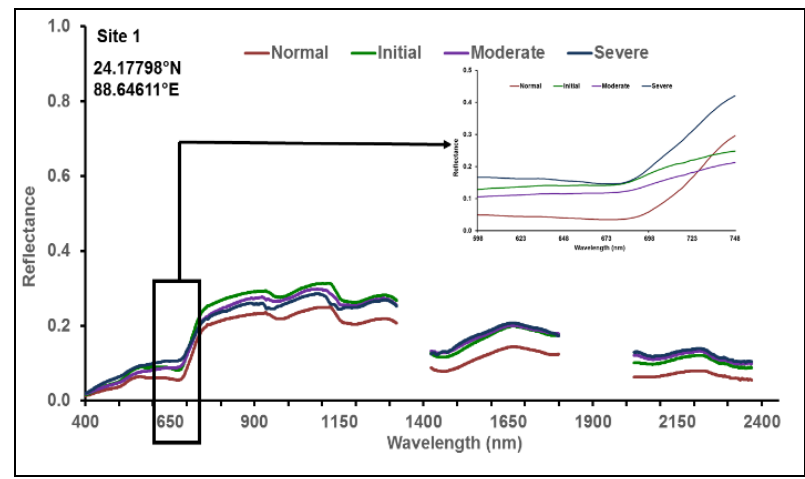

Figure 1. In situ spectral response of healthy and blast infested wheat crop

\subsection{Response of multi-spectral broad band between healthy} and disease infested crop

Ground measured wheat crop signature is converted to Resourcesat-2 AWiFS four multispectral broad bands. Through this process narrow band, signatures are convoluted to broadband signature. The unpaired t-test at 5 per cent level of significance has been applied to test the significance of AWiFS bands in discrimination of healthy and disease infested crop plants. The significant difference is observed for all disease class with respect to healthy wheat crop for all AWiFS bands except than Green spectral band. The two indices NDVI and LSWI are computed using multi-spectral bands of AWiFS computed from ground data. The scatter plot of two indices showed that different cluster for healthy and diseased wheat crop.

\subsection{Discrimination of wheat blast using RS-2 observed AWiFS data}

AWiFS four band data has been used to generate a common wheat spatial crop map over Murshidabad districts using supervised classification with maximum likelihood algorithm. Confusion matrix analysis showed $85.5 \%$ wheat crop classification accuracy with AWiFS data. NDVI and LSWI vary from of 0.1 to 0.7 and 0.1 to 0.5 respectively over Murshidabad district. The generated NDVI and LSWI values over wheat crop pixels are used to generate disease-infested area over the selected district. NDVI and LSWI data is used to generate wheat blast severity map using hierarchical decision tree classification algorithm. In this algorithm, NDVI and LSWI threshold are used based on ground data to distinguish disease class and healthy wheat crop. The confusion matrix of spatial distribution of wheat blast severity map showed $98 \%$ accuracy with kappa coefficient of 0.93 . On the basis of generated wheat severity map only $0.59 \%$ wheat area lies in healthy category whereas, $99.4 \%$ wheat area is infested with wheat blast.

\begin{tabular}{|c|c|c|}
\hline Disease Class & $\begin{array}{c}\text { Wheat Area } \\
\text { (Hectare) }\end{array}$ & $\begin{array}{c}\text { (\%) wheat } \\
\text { area }\end{array}$ \\
\hline Blast infested & 90543.22 & 99.41 \\
\hline Healthy & 542.21 & 0.59 \\
\hline $\begin{array}{c}\text { Total wheat area } \\
\text { (Hectare) }\end{array}$ & 91085.43 & \\
\hline
\end{tabular}

Table 1. Details of wheat area statistics for healthy and wheat blast infested crop

\section{CONCLUSIONS}

The ground observed hyperspectral data at one $\mathrm{nm}$ interval showed that healthy and blast, infested wheat crop can be distinguished in red, red-edge, NIR and SWIR spectral region. The multispectral broad bands of AWiFS are computed using ground spectral data computed from ground data further showed significant difference between healthy and infested crop. Hence, the spectral broad band of AWiFS is able to distinguish healthy and blast infested wheat crop. The degree of infestation is also able to distinguish from broadband AWiFS data. On the basis of NDVI and LSWI threshold derived from ground data the disease infested crop area has been computed using AWiFS data. This study showed that ground based spectral data guide us to discriminate healthy and infested wheat crop at particular district. This study showed that AWiFS data have potential to discriminate healthy and diseased crop at advanced phenological stage of crop with the support of in situ measurements.

\section{ACKNOWLEDGMENTS}

The authors would like to thank, Director, Space Applications Centre, ISRO for his encouragement, motivation and support throughout this study. The authors would also like to thank Dr. Rajkumar, Deputy Director, EPSA (SAC) for constant guidance.

\section{REFERENCES}

Callaway, E. (2016). Devastating wheat fungus appears in Asia for first time. Nature 532, pp. 421-422.

Couch, B.C. and L.M., Kohn. 2002. A multilocus gene genealogy concordant with host preference indicates segregation of a new species, Magnaporthe oryzae, from M.grisea. Mycologia 94, pp. 683-693.

Murakami, J.,Tosa, Y.,Kataoka, T.,Tomita, R.,Kawasaki, J.,Chuma, I.,Sesumi, Y.,Kusaba, M.,Nakayashiki, H., and Mayama, S, 2000. Analysis of host species specificity of Magnaporthe grise toward wheat using a genetic cross between isolates from wheat and foxtail millet. Phytopathology 90:10601067.

Saharan, M.S., S.C. Bhardwaj, R. Chatrath,P. Sharma, A.K. Choudhary, and R.K.Gupta. 2016. Wheat blast disease - An overview Journal of Wheat Research8(1), pp. 1-5.

Tucker, C. J., Justice, C. O. and Prince, S. D. (1986) Monitoring the grasslands of the Sahel 1984-1985. Int. J. Remote Sens., 7, pp. 1571-1579. 